\title{
Loss of Acta2 in cardiac fibroblasts does not prevent the myofibroblast differentiation or affect the cardiac repair after myocardial infarction
}

Yuxia $\mathrm{Li}^{1 *}$, Chaoyang $\mathrm{Li}^{1 *}$, Qianglin $\mathrm{Liu}^{1}$, Leshan Wang ${ }^{1}$, Adam X. Bao ${ }^{2}$, Jangwook P. Jung ${ }^{2}$, Joseph Francis ${ }^{3}$, Jeffery D. Molkentin ${ }^{4}$, and Xing Fu ${ }^{1 \#}$

1. School of Animal Sciences, AgCenter, Louisiana State University, Baton Rouge, LA, USA

2. Department of Biological Engineering, Louisiana State University, Baton Rouge, LA USA.

3. Department of Comparative Biomedical Sciences, School of Veterinary Medicine, Louisiana State University, Baton Rouge, LA, USA

4. Cincinnati Children's Hospital Medical Center (CCHMC), Department of Pediatrics, University of Cincinnati, Cincinnati, Ohio, USA.

* These authors contributed equally to this manuscript.

\# Corresponding author

Contact: Xing Fu, xfu1@agcenter.Isu.edu

\begin{abstract}
In response to myocardial infarction (MI), quiescent cardiac fibroblasts differentiate into myofibroblasts mediating tissue repair in the infarcted area. One of the most widely accepted markers of myofibroblast differentiation is the expression of Acta2 which encodes smooth muscle alpha-actin (SMaA) that is assembled into stress fibers. However, the requirement of Acta2 in the myofibroblast differentiation of cardiac fibroblasts and its role in post-MI cardiac repair were still not known. To answer these questions, we generated a tamoxifen-inducible cardiac fibroblastspecific Acta2 knockout mouse line. Surprisingly, mice that lacked Acta2 in cardiac fibroblasts had a normal survival rate after MI. Moreover, Acta2 deletion did not affect the function or overall histology of infarcted hearts. No difference was detected in the proliferation, migration, or contractility between WT cardiac fibroblasts and Acta2-null cardiac myofibroblasts. Additional analysis identified that Acta2-null cardiac myofibroblasts had a normal total filamentous actin level and total actin level. Acta2 deletion caused a unique compensatory increase in the transcription level of Actg2 and a possible increase in the protein abundance of cytoplasmic actin isoforms. In conclusion, the deletion of Acta2 does not prevent the myofibroblast differentiation of cardiac fibroblasts or affect the post-MI cardiac repair, and the increase in the expression of non-SMaA actin isoforms and the functional redundancy between actin isoforms are likely able to compensate for the loss of Acta2 in cardiac myofibroblasts.
\end{abstract}

\section{INTRODUCTION}

Among cardiovascular diseases (CVDs) which are the leading causes of death in western countries (5), acute myocardial infarction (MI) is one of the most deadly forms due to its unpredictability, fast disease progression, and poor prognosis (1). Following MI, cardiomyocytes in the infarcted myocardium are permanently lost, which greatly compromises the integrity of the infarcted ventricle wall (2). Quiescent cardiac fibroblasts are quickly activated after MI, characterized by massive proliferation and myofibroblast differentiation (3), which is believed to be induced by mechanical stress and cytokine stimulation $(4,5)$. Myofibroblasts mediate the formation of infarct scar through expressing high levels of extracellular matrix (ECM) proteins and 
ECM remodeling enzymes $(3,6)$. In addition, myofibroblasts are also known for the presence of actin stress fibers mostly composed of smooth muscle alpha-actin (SMaA) encoded by Acta2 (7, $8)$. We recently reported that the myofibroblast state of cardiac fibroblasts was largely limited to the first week after MI, after which myofibroblasts further differentiated into matrifibrocytes, a newly identified fibroblast differentiation state lacking the expression of myofibroblast marker genes (3). The transient myofibroblast state of cardiac fibroblasts suggests that myofibroblasts are especially important in the early stage of post-MI cardiac repair. Indeed, depletion of myofibroblasts after MI increased the risk of cardiac rupture during the first week after $\mathrm{MI}(6)$.

Due to the importance of ECM in post-MI tissue healing, the role of cardiac fibroblasts/myofibroblasts in ECM production and remodeling has received special attention (912). However, the function of $\mathrm{SM} \alpha \mathrm{A}$, the hallmark of myofibroblasts, has been largely overlooked. A couple of early in vitro studies manipulating SMaA level or activity found that SMaA promoted fibroblast contraction but inhibited cell migration $(13,14)$. A later study showed that in myofibroblasts SMaA stress fibers play an important role in the formation of supermature focal adhesions which are important for the anchorage of myofibroblasts to the surrounding ECM (15, 16). Several previous studies using mice with global Acta2 deletion to investigate the function of SMaA in myofibroblasts in different disease models suggest that SMaA stress fibers may regulate or affect myofibroblast proliferation, motility, contractility, and ECM remodeling (17-19). However, some discrepancies are present among the results reported by these studies, which suggests that the role and necessity of SMaA in myofibroblasts of different origins may vary significantly. In addition, the deletion of Acta2 in other cell types, such as the vascular smooth muscle cell, may also affect the interpretation of the function of SMaA in studies using global Acta2 knockout (KO) mice.

Here, we studied the function of SMaA in cardiac myofibroblasts and post-MI cardiac repair using a novel tamoxifen-inducible cardiac fibroblast-specific Acta2 KO mouse line and cardiac fibroblast lineage tracing. It was found that Acta2 deletion in cardiac fibroblasts did not significantly affect the post-MI survival or cardiac function of mice. In response to MI or TGF $\beta$ treatment, Acta2-null cardiac fibroblasts underwent normal myofibroblast differentiation, which was likely at least partially due to the compensatory effect of other actin isoforms.

\section{RESULT}

Cardiac fibroblast-specific deletion of Acta2 does not affect post-MI survival, cardiac function, or remodeling in survived mice.

To generate a mouse line with cardiac fibroblast-specific tamoxifen-inducible Acta2 deletion, mice with Acta2 exons 5-7 flanked by loxP sites (Acta2 $\left.{ }^{f / f f}\right)$ were crossed with Tcf21MerCreMer $\left(T c f 21^{M C M /+}\right)$ mice that also carry a Cre-dependent eGFP construct in the Rosa26

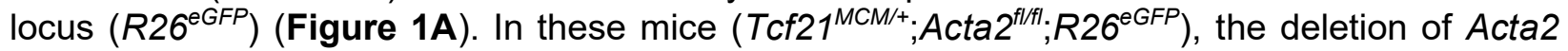
exons 5-7 and expression of eGFP in Tcf21-lineage traced cardiac fibroblasts can be induced by tamoxifen treatment. $T c f 21^{M C M /+} ; A c t a 2^{f / f f l} ; R 26^{\text {eGFP }}$ and $T c f 21^{M C M /+} ; R 26^{e G F P}$ mice were treated with tamoxifen for 5 days to induce Cre activity starting at 6 weeks of age and then subjected to surgeries to induce $\mathrm{Ml}$ at 9 weeks of age (Figure 1B). To maximize the efficiency of Acta2 deletion and reduce the negative effect of prolonged continuous tamoxifen treatment on the viability of mice, another course of tamoxifen treatment was applied to mice from 1 day before $\mathrm{MI}$ to 5 days after MI. A slightly lower survival rate was seen in $T c f 21^{M C M /+} ; A c t a 2^{f / / f l} ; R 26^{e G F P}$ mice than in 
$T c f 21^{M C M /+} ; R 26^{e G F P}$ mice during the first week after MI, however, the difference was not statistically significant as determined by Chi-Square Test $\left(X^{2}(1, n=245)=0.0688, p=0.79\right)$ (Figure 1C). Mice of both groups rarely died after the first week after MI (data not shown), which is consistent with other research showing that most of the fatality happens during the first week after MI when the tissue remodeling is highly active $(6,12)$. Moreover, the cardiac function of the two groups was not significantly different from each other on both days 7 and 28 after MI (Figures 1DE). To study the potential impact of Acta2 deletion on the post-MI cardiac repair and remodeling, heart samples were collected from $T c f 21^{M C M /+} ; A c t a 2^{f / f f l} ; R 26^{e G F P}$ and $T c f 21^{M C M /+} ; R 26^{\text {eGFP }}$ mice on days 7 and 28 after $\mathrm{Ml}$ and subjected to immunohistochemical staining (IHC) for Col1a1 and trichrome staining (Figures 2AB). No difference in the histology and fibrotic response of the heart was observed between $T c f 21^{\mathrm{MCM} /+} ;$ Acta2 $2^{f / f l} ; R 26^{\mathrm{GFP}}$ and $T c f 21^{\mathrm{MCM} /{ }^{+}} ; R 26^{e G F P}$ mice (Figures 2A-C), suggesting relatively normal tissue remodeling in $T c f 21^{M C M /+} ; A c t a 2^{f / f f l} ; R 26^{e G F P}$ mice after MI. The unaffected thinning of the left ventricle free wall and dilation of the left ventricle in Tcf $21^{\mathrm{MCM} / \mathrm{+}} ;$ Acta2 $2^{\mathrm{fl} / f l} ; R 26^{\mathrm{GFF}}$ mice also suggest normal contractility of cardiac fibroblasts lacking Acta2 (Figures 2ABD). The infiltration of Tcf21-lineage traced cardiac fibroblasts into the infarct scar was also not affected by the loss of Acta2 (Figure 2A), suggesting that the motility of cardiac fibroblasts is not affected by the lack of SMaA stress fibers. Together, these results suggest that the loss of SMaA in cardiac myofibroblasts does not affect post-MI cardiac repair or tissue remodeling.

Cardiac fibroblast-specific deletion of Acta2 does not affect the expansion of cardiac fibroblasts in the infarct after MI or their proliferation in vitro.

It was reported that global Acta2 KO led to increased renal fibroblast expansion (17). To study if specific deletion of Acta2 in cardiac fibroblasts also affects their post-MI expansion, a 5Ethynyl-2'-deoxyuridine (EdU)-based in vivo proliferation assay was performed. Using this method, we previously identified that the proliferation of cardiac fibroblasts after MI peaked at day 3 after MI and was largely diminished beyond day 7 post-MI (3). Thus, a single EdU injection was given to mice on days 3 or 7 after MI, followed by sample collection 4 hours after EdU injection. EdU and Ki67 staining showed that the post-MI proliferation of Tcf21-lineage traced cardiac fibroblasts was not different between $T c f 21^{M C M /+} ; A c t a 2^{f / f t /} ; R 26^{e G F P}$ and $T c f 21^{M C M /+} ; R 26^{e G F P}$ mice, despite the efficient cardiac fibroblast-specific Acta2 deletion in $T c f 21^{M C M /+} ; A c t a 2^{f / / f l} ; R 26^{e G F P}$ mice indicated by the absence of SMaA expression in Tcf21 lineage-traced cardiac fibroblasts (Figure $3 A B)$. To verify these findings in vitro, cardiac fibroblasts were isolated from Acta $^{f / f f l}$ and WT mice, treated with adenoviruses expressing Cre (Adeno-Cre), and induced for myofibroblast differentiation by TGF $\beta$ treatment. No difference in the percentage of cells expressing Ki67 was observed between the 2 groups (Figure 3C). A proliferation assay was also performed by coculturing TGF $\beta$ - and Adeno-Cre-treated cardiac fibroblasts isolated from Acta2 $2^{f / f f l} ; R 26^{e G F P}$ mice and $R 26^{\text {tdTomato }}$ mice (tdTomato is expressed in response to Adeno-Cre) mixed at a 1:1 ratio. The ratio remained the same after 48 hours of incubation, further suggesting that Acta2 deletion does not affect the proliferation of cardiac fibroblasts (Figure 3D).

Cardiac myofibroblasts lacking Acta2 have normal motility, contractility, and matrix stabilization ability.

Besides the unaffected cardiac fibroblast proliferation, in vivo experiments using $T c f 21^{M C M /+} ; R 26^{\text {GFFP }}$ and Tcf $21^{M C M /+} ; A c t a 2^{f / / f l} ; R 26^{e G F P}$ mice also suggest that the deletion of Acta2 in cardiac fibroblasts does not affect their motility and contractility after MI (Figures 2A-D). To verify these results in more controlled environments, the effects of Acta2 deletion on the motility 
and contraction of cardiac fibroblasts were tested in vitro. For a direct comparison of motility, Adeno-Cre-treated Acta2 $2^{f / f t} ; R 26^{\text {eGFP }}$ cardiac fibroblasts and $R 26^{\text {tdTomato }}$ cardiac fibroblasts cocultured at 1:1 ratio were monitored for their migration toward the center of the well. No difference was observed between the 2 groups in the presence or absence of TGF $\beta$ (Figure 4). To better simulate the 3D matrix environment in the infarct, the same experiment was repeated with the addition of a layer of collagen gel cast on top of the cocultured cardiac fibroblasts. However, again no difference was observed (Figure 4). To test the effect of Acta2 deletion on the contractility of cardiac fibroblasts, a gel contraction assay was performed using cardiac fibroblasts isolated from Acta ${ }^{f / / f l}$ and WT mice and treated with Adeno-Cre and TGF $\beta$, which showed no difference between the 2 groups (Figure 5A). It has been shown that cells can function as a crosslinker to strengthen the mechanical property of the matrix (20), a possible mechanism through which cardiac fibroblasts/myofibroblasts maintain the structural integrity of the infarct. Thus, we employed rheology to test the effect of cardiac fibroblasts on the stability of the collagen gel they reside in. In rheology, the storage modulus indicates the ability of the material to store deformation energy in an elastic manner while maintaining structural integrity and has been used to measure the strength of biomaterials (21-23). Hydrogels with a greater level of crosslinking have a higher storage modulus (24). Cardiac fibroblasts isolated from Acta2 ${ }^{f / f f}$ and WT mice were treated with Adeno-Cre and TGF $\beta$, mixed with collagen gel, and culture for 24 hours to allow for the development of tension, followed by tests using a rheometer. The presence of cardiac fibroblasts increased the storage modulus of collagen gels (Figure 5B). However, no significant difference was observed in the storage modulus between collagen gels laden with WT myofibroblasts and those laden with Acta2-null myofibroblasts. This suggests that the loss of Acta2 does not affect the matrix stabilization capacity of myofibroblasts, which is consistent with the similar survival rates between $T c f 21^{M C M /+} ; R 26^{\text {eGFP }}$ and $T c f 21^{M C M /+} ;$ Acta $^{f / f t /} ; R 26^{e G F P}$ mice.

\section{Acta2 deletion in cardiac fibroblasts does not prevent myofibroblast differentiation.}

Studies using global Acta2 KO mice showed that the deletion of Acta2 did not seem to prevent the formation of F-actin stress fiber in myofibroblasts derived from fibroblasts of several different organs (17-19). To test if this was also the case in cardiac fibroblasts, cardiac fibroblasts were isolated from Acta2 $2^{f / f l}$ and WT mice, treated with Adeno-Cre, and induced for myofibroblast differentiation using TGF $\beta$. Immunocytochemical staining (ICC) using an antibody against SMaA and phallodin staining showed that the amount of F-actin stress fibers was not significantly different between WT and Acta2-null cardiac myofibroblasts (Figure 6A). To specifically study the effect of Acta2 deletion on the myofibroblast differentiation of Tcf21 lineage-traced cardiac fibroblasts, cardiac fibroblasts were isolated from tamoxifen-treated $T c f 21^{M C M /+} ;$ Acta $2^{f / / f l} ; R_{2} 26^{e G F P}$ and $T c f 21^{M C M /+} ; R 26^{e G F P}$ mice and cultured in a medium supplemented with TGF $\beta$. ICC showed the lack of SMaA expression in most Tcf21 lineage-traced cardiac myofibroblasts from $T c f 21^{M C M /+} ; A c t a 2^{f / f f l} ; R 26^{\text {eGFP }}$ mice but not in Tcf21 lineage-traced cardiac myofibroblasts from Tcf2 $1^{M C M /+} ; R 26^{e G F P}$ mice (Figure 6B). However, no difference was observed in the total F-actin level between Tcf21 lineage-traced cardiac myofibroblasts of the 2 groups of mice (Figure 6B). In the meantime, no difference in the expression of SMaA or F-actin level was observed between non-Tc21 lineage-traced cardiac myofibroblasts of the 2 groups of mice (Figure 6B). Similarly, on day 7 after $\mathrm{Ml}$ the amount of F-actin stress fibers in Tcf21 lineage-traced cardiac fibroblasts in the infarct scar of $T c f 21^{M C M /+} ;$ Acta2 $^{f / f f l} ; R 26^{\text {eGFP }}$ mice was similar compared to that in $T c f 21^{M C M /+} ; R 26^{\text {eGFP }}$ mice (Figure 6C). Stress fibers guide the maturation of focal adhesion (25). We then questioned if the reduced amount of stress fibers in Acta2-null cardiac fibroblasts had an effect on focal adhesion. ICC using an anti-vinculin antibody showed that Acta2 deletion did 
not significantly affect the abundance of mature focal adhesion (Figure 6D). These results suggest that the deletion of Acta2 in cardiac fibroblasts does not prevent myofibroblast differentiation.

\section{Compensatory increase in the expression of non-SMaA actin isoforms in Acta2-null cardiac myofibroblasts.}

Besides Acta2/SMaA, 5 other actin isoforms are also expressed in mice, including Acta1 (skeletal muscle alpha-actin, SkMaA), Actb (cytoplasmic beta-actin, CyßA), Actc1 (cardiac muscle alpha-actin, CMaA), Actg1 (cytoplasmic gamma-actin, CyyA), and Actg2 (smooth muscle gammaactin, SMyA). The normal myofibroblast differentiation of Acta2-null cardiac fibroblasts suggests a functional redundancy between different actin isoforms and a possible compensatory increase in the expression of other actin isoforms. To explore these possibilities, we first examined the relative expression levels of different actin isoforms in cardiac fibroblasts after $\mathrm{Ml}$ using our recently published RNA-seq data obtained using Tcf21 lineage-traced cardiac fibroblasts isolated from uninjured hearts and infarct scars at different days after MI (26). The result showed that even though Acta2 was the most upregulated actin isoform in cardiac myofibroblasts after MI, the expression of Actb, Actg1, and Actg2 were also upregulated. Moreover, in cardiac myofibroblasts Actg1 was expressed at a level comparable to Acta2 and the expression of Actb was twice as high as Acta2 (Figure 7A). Adeno-Cre- and TGF $\beta$-treated WT and Acta2 $2^{\text {flffl }}$ cardiac fibroblasts were then compared to study the impact of Acta2 on the expression of other actin isoforms by realtime PCR. A unique upregulation in the expression of Actg2 but not other actin isoforms was identified in Acta2-null cardiac myofibroblasts as compared to the WT control (Figure 7B). To understand the effect of Acta2 deletion on the protein level of other actin isoforms, we performed ICC using antibodies against different actin isoforms. ICC using an antibody that recognizes sarcomeric actin isoforms (SkMaA and CMaA) showed that the expression of SkMaA and CMaA in most WT and Acta2-null cardiac myofibroblasts was very low (Figure 7C), which was consistent with RNA-seq data. The combined protein level of SkMaA and CMaA in Acta2-null cardiac myofibroblasts was not significantly different from that in WT cardiac myofibroblasts except for a very small number of Acta2-null cardiac myofibroblasts showing an elevated level of SkMaA or/and $\mathrm{CM \alpha A}$, which suggests that sarcomeric actin isoforms do not significantly compensate for the loss of SMaA (Figure 7C). Co-staining with an antibody recognizing smooth muscle actin isoforms (SMaA and SMYA) showed that the combined protein level of SMaA and SMyA in Acta2null cardiac myofibroblasts was significantly lower than that in WT cardiac myofibroblasts, suggesting that $\mathrm{SMaA}$ is the dominant smooth muscle actin isoform in cardiac myofibroblasts and the increased expression of Actg2 identified by realtime PCR does not fully compensate for the loss of SMaA (Figure 7C). Interestingly, western blot and ICC analyses of Adeno-Cre- and TGF $\beta$ treated WT and $A c t a 2^{f / f l}$ cardiac fibroblasts showed that the total actin protein level was not different between the 2 groups (Figures 7DE). Given the limited compensatory increase in the expression of other muscle actin isoforms in Acta2-null cardiac myofibroblasts, the unaffected total actin protein level in these cells likely also involved an increased abundance of cytoplasmic actin isoforms, which was possibly due to increased translational efficiency or protein stability of these actin isoforms since no increase in their mRNA expression was identified.

\section{DISCUSSION}

Myofibroblasts with a highly developed cytoplasmic fibrillar system were first identified in skin wounds (27). Later studies found that these cells express an elevated level of SMaA which is incorporated into stress fibers (28-30). Ever since SMaA stress fiber has been used as a marker 
for myofibroblast differentiation. Due to the specific expression of SMaA in myofibroblasts, it was speculated that SMaA stress fiber may play an important role in multiple myofibroblast activities involved in wound healing such as contraction, motility, and myofibroblast proliferation. However, in this study, using a newly generated mouse line with tamoxifen-inducible cardiac fibroblastspecific deletion of Acta2, we identified that the loss of Acta2 did not significantly affect the myofibroblast differentiation of cardiac fibroblasts. No difference in contractility, matrix stabilization ability, proliferation, or motility was observed between WT and Acta2-null cardiac myofibroblasts. In line with results obtained in vitro, mice lacking Acta2 in cardiac fibroblasts also had normal post-MI survival rate, cardiac repair, and cardiac function.

Due to the contractile function of vascular smooth muscle cells, which also express a high level of $\mathrm{SM} \alpha \mathrm{A}$, the role of $\mathrm{SM} \alpha \mathrm{A}$ in the contractility of myofibroblasts received special attention. It was found that overexpression of Acta2 increased the contractility of 3T3 fibroblasts more significantly than the overexpression of Actb, Actg1, or Actc1, even though the incorporation of all actin isoforms into stress fibers was identified (31). Disruption of the SMaA stress fiber structure using an SMaA fusion peptide containing the N-terminal of SMaA (32) reduced adhesion and contractility of rat embryo fibroblast cell line REF-52 (15). Besides these early studies of the function of SMaA stress fibers that were mainly performed in vitro using cell lines, the function of SMaA stress fibers in primary myofibroblasts and their role during tissue healing were recently studied by a few groups using whole-body Acta2 KO mice (17-19). Deletion of Acta2 was reported to reduce the contractility of hepatic stellate cells-derived myofibroblasts (19). However, it was found that mice lacking Acta2 had normal skin wound closure and the contractility of skin fibroblasts isolated from these mice was not different from those isolated from WT mice (18), which was similar to the effect of Acta2 $\mathrm{KO}$ on cardiac fibroblasts observed in the current study.

Besides the contractile function of myofibroblasts, previous studies have also investigated the effects of SMaA stress fibers on myofibroblast motility, proliferation, and ECM production. A study inhibiting SM $\alpha A$ function using a neutralization antibody identified that the motility of breast tissue-derived myofibroblasts was enhanced when SMaA function was inhibited (14). Another study found that renal fibroblasts isolated from Acta2-null mice had enhanced motility and proliferation in vitro (17). In addition, the same study also identified an elevated level of collagen production by Acta2-null renal myofibroblasts, which exacerbated renal fibrosis. In contrast, the deletion of Acta2 reduced the collagen expression by myofibroblasts Acta2-null hepatic stellate cells (19). Our study, however, did not identify a significant change in any of these myofibroblast functions and activities in cardiac myofibroblasts owing to Acta2 deletion. Moreover, a study reported that cells increased the stability of the matrix through acting as a crosslinker (20). Stress fibers play an important role in the maturation of focal adhesion, the contact point between cells and matrix $(14,25)$. The actin stress fiber network in cardiac myofibroblasts is interconnected with the surrounding ECM through focal adhesion and likely function as a structural support lattice to stabilize the early infarct scar before the scar ECM is mature enough to prevent cardiac rupture. The lack of difference in the abundance of stress fiber between WT and of Acta2 KO cardiac fibroblasts likely also explains the normal survival rate of cardiac fibroblast-specific Acta2 KO mice.

The reason for the large discrepancy between results generated by different studies of the SMaA function may be multifaceted. First, it is well known that immortalized cell lines, which were used by many early studies, often act significantly differently from primary cells. Second, the experimental procedure of studies using SMaA fusion peptide and neutralization antibodies often included acute treatment of myofibroblasts with SMaA fusion peptide or antibody to disrupt SMaA 
stress fibers followed by functional analyses. This strategy likely did not provide other actin isoforms with enough time to develop a compensatory effect. Indeed, even though Acta2-null mice had normal skin wound contraction (18), a study applying SMaA fusion peptide to skin wounds in vivo significantly inhibited rat skin wound contraction (33). Third, the inconsistent results of research focusing on fibroblasts or fibroblast-like cells in different organs using Acta2 $\mathrm{KO}$ mice likely reflect the difference in the adaptation of these cells to Acta2 deletion. Unlike Acta2-null cardiac and skin myofibroblasts that have normal contractility, a study using Acta2 KO mice reported a reduction in the contractility of myofibroblasts derived from hepatic stellate cells (19). In the current study, a 3-fold increase in the transcription of Actg2, the only other actin isoform expressed in smooth muscle, was identified in Acta2-null cardiac myofibroblasts as compared to WT cardiac myofibroblasts. A similar increase in the expression of other muscle actin isoforms was also identified in Acta2-null skin myofibroblasts when compared to the WT control (18). A similar increase in the expression of non-SM $\alpha$ A muscle actin isoforms was however not identified in myofibroblasts derived from Acta2-null hepatic stellate cells (19). Instead, an increase in the expression of cytoplasmic actin isoforms was detected in these cells compared to their WT counterparts. It is possible that without the guidance of stress fibers formed by muscle actin isoforms the ability of non-muscle actin isoforms to form stress fibers is relatively limited, which likely contributed to the more impacted contractile function of Acta2-null hepatic stellate cell-derived myofibroblasts.

It is worth noting that even though the deletion of Acta2 in cardiac fibroblasts does not prevent their myofibroblast differentiation, it does mean that actin stress fibers or the myofibroblast state are dispensable for the post-MI cardiac repair. In contrast, due to the importance of myofibroblasts, a sophisticated gene expression network is likely present in cardiac fibroblasts to ensure their successful myofibroblast differentiation even when the expression of certain myofibroblast functional genes is disrupted. A study disrupting the formation of stress fibers by all actin isoforms is needed in the future to better decipher the function of actin stress fibers in myofibroblasts and post-injury tissue repair.

Taken together, our results indicate that the expression of Acta2/SMaA is not required for the myofibroblast differentiation of cardiac fibroblasts and their activities in post-MI cardiac repair, which is at least partially due to the compensatory increase in the expression of other actin isoforms and the functional redundancy between SMaA and non-SMaA actin isoforms. Our study also suggests that significant heterogeneity is present within the over-simplified fibroblast and fibroblast-like cell types.

\section{Method}

\section{Mice.}

Mouse embryonic stem cells with a "knockout-first" Acta2 allele purchased from European Mouse Mutant Cell Repository were used to generate chimeric mice. Chimeric mice were crossed with WT C57BL/6 mice to obtain offsprings carrying the mutant allele which were then crossed with mice expressing FLPe recombinase (Jackson Laboratory, \#003946) to delete the LacZ-neo cassette upstream of exon 5 of Acta2 to generate Acta2 ${ }^{\text {fllt }}$ mice with exons 5 to 7 of Acta2 flanked by loxP sites. $T c f 21^{M C M /+}(34)$ and $R 26^{e G F P}(35)$ mice were crossed to generate $T c f 21^{M C M /+} ; R 26^{e G F P}$ mice. Acta2 $2^{\mathrm{fll}+}$ mice were crossed with $T c f 21^{\mathrm{MCM} /+} ; R 26^{\mathrm{eGFP}}$ mice to generate $T c f 21^{M C M /+} ; A c t a 2^{f / f f l} ; R 26^{e G F P}$ mice. $R 26^{\text {tdTomato }}$ mice were purchased from Jackson Laboratory (\#007914). 


\section{Antibodies and biologics.}

Anti-eGFP (ab13970) and anti-Col1(ab34710) antibodies were purchased from Abcam. Anti-Ki67 antibody (9129S) and Alexa Fluor ${ }^{\circledR} 647$ Phalloidin (8940S) were purchased from Cell Signaling Technology. Anti-SMaA (113200), anti-SkMaACMaA (A2172), and anti-SMa/yA (A7607) antibodies were purchased from Millipore Sigma. Pan anti-actin and anti- $\beta$-tubulin antibodies were purchased from DSHB. Anti-vinculin (NB600-1293) antibody was purchased from Novus. Goat anti-mouse IgG2a Alexa Fluor 488 (A-21131), goat anti-mouse IgG2b Alexa Fluor 488 (A21141), goat anti-mouse IgM Alexa Fluor 488 (A-21042), goat anti-mouse IgG2a Alexa Fluor 555 (A-21137), goat anti-mouse IgG1 Alexa Fluor 555 (A-21127), goat anti-rabbit IgG Alexa Fluor 555 (A-21428), goat anti-mouse IgG Alexa Fluor 647 (A-21235), and goat anti-chicken IgY Alexa Fluor 488 (A-11039) antibodies were purchased from Thermo Scientific. EdU (catalog sc-284628A) was purchased from Santa Cruz Biotechnology Inc. Collagenase D (catalog 11088866001) and Dispase II (catalog 4942078001) were purchased from Roche Diagnostics. Collagen, type I (356236) was purchased from Corning. TGF- $\beta$ (240-B) was purchased from R\&D Systems.

\section{Animal procedures.}

To induce the activity of the MerCreMer protein, mice were treated with tamoxifen (MilliporeSigma, T5648) dissolved in corn oil through i.p. injections or gavage at a dosage of $75 \mathrm{mg} / \mathrm{kg}$ body weight/day for 5 days starting at 6 weeks of age. Mice were subjected to permanent surgical ligation of the left coronary artery to induce MI at 9 weeks of age (36). Briefly, mice were anesthetized using isoflurane and a left lateral thoracotomy was performed. The left coronary artery was identified and ligated just below the left atrium. To ensure the efficient deletion of Acta2, mice were given another course of tamoxifen treatment from 1 day before MI to 5 days after MI. Echocardiography was performed in M-mode using a Toshiba Aplio SSA-770a ultrasound system and a 12-MHz transducer as previously described (37). For pain management related to surgical procedures, mice were given a dose of Carprofen ( $5 \mathrm{mg} / \mathrm{kg}$ body weight) before the surgery followed by a second dose 12 hours after the surgery. Mice were checked every day after Ml for survival rate. Mice found dead were subjected to necropsy to identify cardiac rupture.

\section{EdU in vivo fibroblast proliferation assay.}

Mice were treated with EdU at a dosage of $50 \mathrm{mg} / \mathrm{kg}$ body weight through i.p. injections. Four hours after EdU injections, mice were sacrificed, and heart samples were collected. EdU detection was carried out after IHC staining using the Click-iT Plus Alexa Fluor 647 Picolyl Azide Toolkit (C10643) from Thermo Fisher Scientific.

\section{Cell isolation and culture.}

Cardiac fibroblasts were isolated as previously described (3). Briefly, heart tissue was minced and digested in DMEM containing $0.75 \mathrm{U} / \mathrm{ml}$ collagenase $\mathrm{D}$ (Roche, 11088866001), $1.0 \mathrm{U} / \mathrm{ml}$ Dispase II (Roche, 10165859001), and $1 \mathrm{mM} \mathrm{CaCl}$ at $37^{\circ} \mathrm{C}$ for 40 minutes. The slurry was then passed through a $100 \mu \mathrm{m}$ cell strainer and then a $40 \mu \mathrm{m}$ cell strainer. Cells were collected by centrifugation at $350 \mathrm{~g}$ for 10 minutes. The cell pellets were resuspended in a growth medium composed of DMEM with $10 \%$ bovine growth serum (BGS) and $1 \%$ of an antibiotic mixture containing 10,000 U/ml penicillin, $10 \mathrm{mg} / \mathrm{ml}$ streptomycin, and $25 \mu \mathrm{g} / \mathrm{ml}$ amphotericin B and seeded on cell culture plates. To induce Acta2 deletion, WT and Acta2 $2^{f / f t}$ cardiac fibroblasts were treated with Adeno-Cre. Myofibroblast differentiation was induced by TGF $\beta(10 \mathrm{ng} / \mathrm{ml})$ treatment for 2 days. 


\section{Gel contraction assay.}

Gel contraction assay was performed as previously described with some modifications. Briefly, $50,000$ cardiac fibroblasts that had been treated with TGF $\beta$ (10 $\mathrm{ng} / \mathrm{ml})$ and Adeno-Cre were resuspended in $0.4 \mathrm{ml}$ of growth medium and mixed with $0.2 \mathrm{ml}$ of collagen solution that contains $0.1 \%$ acetic acid. $4 \mu \mathrm{l}$ of $1 \mathrm{M} \mathrm{NaOH}$ was added to neutralize the acetic acid. $0.5 \mathrm{ml}$ of the mixture was added to each well of 24 well plates and allowed to solidify at room temperature for $30 \mathrm{~min}$, followed by the addition of $0.5 \mathrm{ml}$ of growth medium supplemented with TGF $\beta .12$ hours after the incubation at $37^{\circ} \mathrm{C}$, gels were carefully released from the well to allow the contraction.

\section{Rheology.}

Cell-free and cell-laden collagen gels were made and cultured as described above. After 24 hours of incubation, collagen gels were released and trimmed using a $5 \mathrm{~mm}$ biopsy punch. Using a TA Discovery HR-2 rheometer and a $5 \mathrm{~mm}$ crosshatched plate, the storage moduli of gels were determined by frequency sweeping from 6.28 to 25.13 (rad/s) at $2 \%$ strain and $10 \%$ compression.

\section{Cell motility assay.}

Cell motility assay was performed using Oris Cell Migration Assembly Kit (Platypus Technologies) following the manufacturer's protocol with some modifications. Briefly, TGF $\beta(10 \mathrm{ng} / \mathrm{ml})$ and Adeno-Cre-treated $R 26^{\text {tdTomato }}$ and $A c t a 2^{f / f f l} ; R 26^{\text {eGFP }}$ cardiac fibroblasts were mixed at a $1: 1$ ratio. A total of 40,000 cells were seeded into each well of 96 well plates with a stopper placed in the center of the well. Cells were cultured in a maintenance medium containing DMEM with $0.5 \%$ BGS and $1 \%$ of an antibiotic mixture at $37{ }^{\circ} \mathrm{C}$ overnight before the removal of stoppers. A quick rinse with PBS was performed, followed by the addition of a fresh maintenance medium with or without TGF $\beta$. For the 3D migration test, after the rinse, $0.5 \mathrm{ml}$ neutralized collagen solution (3 $\mathrm{mg} / \mathrm{ml}$ ) was added to each well and allowed to solidify before adding fresh maintenance medium with or without TGF $\beta$. The migration of cells into the center of the well was monitored.

\section{Realtime PCR.}

Realtime PCR was performed as previously described (38). Briefly, RNA was extracted using a Direct-zol RNA Microprep Kit (Zymo). cDNA was synthesized using an iScript cDNA Synthesis Kit (Bio-Rad). Realtime PCR was carried out using a CFX RT-PCR detection system (Bio-Rad) with SsoAdvanced Universal SYBR Green Supermix (Bio-Rad). Relative mRNA content was normalized to $18 \mathrm{~S}$ rRNA content. The primers used are listed in table 1.

\section{Western blot.}

Western blot was performed as previously described (39) with some modifications. Briefly, cells were lysed in RIPA buffer with Halt Protease Inhibitor Cocktail (Thermo Scientific) to extract the protein. SDS-PAGE and blotting were performed using Bio-Rad Mini-PROTEAN Electrophoresis System. After the immunostaining, images were taken using a ProteinSimple FluorChem $\mathrm{R}$ System. Band density was normalized to $\beta$-tubulin content.

\section{Immunocytochemical staining.}

Cells grown on multiple-chamber slides or multiple well plates were fixed in $4 \%$ paraformaldehyde (PFA) for 10 minutes, rinsed 3 times in TBS with $0.1 \%$ Triton $X-100$, incubated in blocking buffer (TBS, $0.1 \%$ Triton $\mathrm{X}-100$, and $3 \% \mathrm{BSA}$ ), and then incubated with primary antibodies diluted in blocking buffer overnight at $4^{\circ} \mathrm{C}$. Cells were then rinsed in TBS with $0.1 \%$ Triton $\mathrm{X}-1003$ times 
and stained with corresponding secondary antibodies diluted in blocking buffer for 1 hour at room temperature. Stained slides were then rinsed and mounted in a mounting medium containing DAPI (Vector Laboratories). Images were captured using an Echo Revolve microscope. Signal strength was determined using ImageJ.

\section{IHC staining.}

IHC staining was performed as previously described (3). Briefly, mouse heart samples were fixed in 4\% PFA, incubated in 30\% sucrose dissolved in PBS, and embedded in OCT (Tissue-Tek) for cryosectioning. Cryosections ( $5 \mu \mathrm{m}$ thick) were blocked with $5 \%$ goat serum and $0.2 \%$ Triton $\mathrm{X}$ 100 diluted in TBS, incubated in primary antibodies diluted in blocking buffer overnight at $4^{\circ} \mathrm{C}$, and then incubated in appropriate fluorophore-conjugated secondary antibodies diluted in blocking buffer for 1 hour at room temperature. Stained sections were then mounted in a mounting medium containing DAPI (Vector Laboratories). Images were captured using a Leica SP8X confocal microscope.

\section{Trichrome staining.}

Trichrome staining was performed using reagents for Masson's Trichrome for Connective Tissue (Electron Microscopy Sciences) following the manufacturer's protocol. ) Percentage of the fibrotic area in the left ventricle and average left ventricle thickness at 3 different segments were determined using ImageJ.

\section{Statistics.}

All data are expressed as mean \pm SEM unless otherwise stated. Data were analyzed using GraphPad Prism 9 (GraphPad Software, Inc.). Two-tailed $t$ test was used to determine the significance of differences between the 2 groups. One-way ANOVA with post hoc Tukey's test was used to determine the significance of difference when more than 2 groups were compared. Chi-Square Test was used to determine the significance of difference between the survival rates of Tcf $21^{M C M /+} ; R 26^{e G F P}$ and $T c f 21^{M C M /+} ;$ Acta2 $^{f / f f l} ; R 26^{e G F P}$ mice. $P<0.05$ was considered significant.

\section{Study approval.}

All experiments involving mice were approved by the IACUC at LSU (approval number IACUC 18-024).

\section{Author contribution}

X.F. conceived the study; Y.L., C.L., Q.L., L.W., and A.B. performed experiments. Y.L., C.L., and J.J.. analyzed data. Y.L, C.L., J.F., J.M., and X.F. interpreted the data, assembled the results, and wrote the manuscript with inputs from all authors.

\section{Funding details}

This work was supported by the Louisiana Board of Regents under grant BOR.Fu.LEQSF(2019-22)-RD-A-01 (X.F.); NIH/NIDDK under grant 1R15DK122383 (X.F.); NIH/NIGMS P20GM130555 (X.F.); and NIH/NHLBI R01HL142217 (J.M.).

\section{Disclosure statement}

The authors declare no competing interests. 
bioRxiv preprint doi: https://doi.org/10.1101/2021.05.20.445043; this version posted May 21, 2021. The copyright holder for this preprint (which was not certified by peer review) is the author/funder. All rights reserved. No reuse allowed without permission. 


\section{References}

1. Priebe H-J. Perioperative myocardial infarction-aetiology and prevention. $\mathrm{Br} \mathrm{J}$ Anaesth. 2005;95(1):3-19. PubMed PMID: 15665072.

2. Yellon DM, Hausenloy DJ. Myocardial reperfusion injury. New Engl J Med. 2007;357(11):1121-35. Epub 2007/09/15. doi: 10.1056/NEJMra071667. PubMed PMID: 17855673.

3. Fu X, Khalil H, Kanisicak O, Boyer JG, Vagnozzi RJ, Maliken BD, Sargent MA, Prasad V, Valiente-Alandi I, Blaxall BC, Molkentin JD. Specialized fibroblast differentiated states underlie scar formation in the infarcted mouse heart. J Clin Investig. 2018;128(5):2127-43. doi: 10.1172/JCI98215; PMCID: PMC5957472.

4. Davis J, Molkentin JD. Myofibroblasts: trust your heart and let fate decide. J Mol Cell Cardiol. 2014;70:9-18. Epub 2013/11/06. doi: 10.1016/j.yjmcc.2013.10.019. PubMed PMID: 24189039; PMCID: PMC3995855.

5. $\quad$ Hinz B. Myofibroblasts. Exp Eye Res. 2016;142:56-70. PubMed PMID: 26192991.

6. Kanisicak O, Khalil H, Ivey MJ, Karch J, Maliken BD, Correll RN, Brody MJ, SC JL, Aronow BJ, Tallquist MD, Molkentin JD. Genetic lineage tracing defines myofibroblast origin and function in the injured heart. Nat Commun. 2016;7:12260. Epub 2016/07/23. doi: 10.1038/ncomms12260. PubMed PMID: 27447449; PMCID: PMC5512625.

7. Darby I, Skalli O, Gabbiani G. a-Smooth muscle actin is transiently expressed by myofibroblasts during experimental wound healing. Lab Invest. 1990;63(1):21-9.

8. Leslie KO, Taatjes DJ, Schwarz J, vonTurkovich M, Low RB. Cardiac myofibroblasts express alpha smooth muscle actin during right ventricular pressure overload in the rabbit. Am J Pathol. 1991;139(1):207-16. PubMed PMID: 1853934.

9. Xiang F-L, Fang M, Yutzey KE. Loss of $\beta$-catenin in resident cardiac fibroblasts attenuates fibrosis induced by pressure overload in mice. Nat Commun. 2017;8(1):712. doi: 10.1038/s41467017-00840-w.

10. Khalil H, Kanisicak O, Vagnozzi RJ, Johansen AK, Maliken BD, Prasad V, Boyer JG, Brody MJ, Schips T, Kilian KK, Correll RN, Kawasaki K, Nagata K, Molkentin JD. Cell-specific ablation of Hsp47 defines the collagen-producing cells in the injured heart. JCI Insight. 2019;4(15). doi: 10.1172/jci.insight. 128722.

11. Bageghni SA, Hemmings KE, Yuldasheva NY, Maqbool A, Gamboa-Esteves FO, Humphreys NE, Jackson MS, Denton CP, Francis S, Porter KE, Ainscough JFX, Pinteaux E, Drinkhill MJ, Turner NA. Fibroblast-specific deletion of IL-1 receptor-1 reduces adverse cardiac remodeling following myocardial infarction. JCl Insight. 2019;4(17). doi: 10.1172/jci.insight.125074.

12. Kaur H, Takefuji M, Ngai CY, Carvalho J, Bayer J, Wietelmann A, Poetsch A, Hoelper S, Conway SJ, Mollmann H, Looso M, Troidl C, Offermanns S, Wettschureck N. Targeted Ablation of Periostin-Expressing Activated Fibroblasts Prevents Adverse Cardiac Remodeling in Mice. Circ Res. 2016;118(12):1906-17. Epub 2016/05/04. doi: 10.1161/CIRCRESAHA.116.308643. PubMed PMID: 27140435.

13. Hinz B, Celetta G, Tomasek JJ, Gabbiani G, Chaponnier C. Alpha-smooth muscle actin expression upregulates fibroblast contractile activity. Mol Biol Cell. 2001;12(9):2730-41.

14. Rønnov-Jessen L, Petersen OW. A function for filamentous alpha-smooth muscle actin: retardation of motility in fibroblasts. J Cell Biol. 1996;134(1):67-80.

15. Hinz B, Dugina V, Ballestrem C, Wehrle-Haller B, Chaponnier C. a-Smooth muscle actin is crucial for focal adhesion maturation in myofibroblasts. Mol Biol Cell. 2003;14(6):2508-19.

16. Zaidel-Bar R, Cohen M, Addadi L, Geiger B. Hierarchical assembly of cell-matrix adhesion complexes. Biochem Soc Trans. 2004;23(Pt3):416-20.

17. Takeji M, Moriyama T, Oseto S, Kawada N, Hori M, Imai E, Miwa T. Smooth muscle alphaactin deficiency in myofibroblasts leads to enhanced renal tissue fibrosis. J Biol Chem. 
2006;281(52):40193-200. Epub 2006/11/09. doi: 10.1074/jbc.M602182200. PubMed PMID: 17090535.

18. Tomasek JJ, Haaksma CJ, Schwartz RJ, Howard EW. Whole animal knockout of smooth muscle alpha-actin does not alter excisional wound healing or the fibroblast-to-myofibroblast transition. Wound Repair Regen. 2013;21(1):166-76.

19. Rockey DC, Du Q, Shi Z. Smooth Muscle a-Actin Deficiency Leads to Decreased Liver Fibrosis via Impaired Cytoskeletal Signaling in Hepatic Stellate Cells. Am J Pathol. 2019;189(11):2209-20. doi: https://doi.org/10.1016/j.ajpath.2019.07.019.

20. Lee KY, Kong HJ, Larson RG, Mooney DJ. Hydrogel formation via cell crosslinking. Advanced Materials. 2003;15(21):1828-32.

21. Tunick MH, Malin EL, Smith PW, Shieh JJ, Sullivan BC, Mackey KL, Holsinger V. Proteolysis and rheology of low fat and full fat Mozzarella cheeses prepared from homogenized milk. J Dairy Sci. 1993;76(12):3621-8.

22. Jung JP, Lin WH, Riddle MJ, Tolar J, Ogle BM. A 3D in vitro model of the dermoepidermal junction amenable to mechanical testing. Journal of Biomedical Materials Research Part $A$. 2018;106(12):3231-8.

23. Van Den Bulcke Al, Bogdanov B, De Rooze N, Schacht EH, Cornelissen M, Berghmans $\mathrm{H}$. Structural and rheological properties of methacrylamide modified gelatin hydrogels. Biomacromolecules. 2000;1(1):31-8.

24. Grattoni CA, Al-Sharji HH, Yang C, Muggeridge AH, Zimmerman RW. Rheology and permeability of crosslinked polyacrylamide gel. J Colloid Interface Sci. 2001;240(2):601-7.

25. Oakes PW, Beckham Y, Stricker J, Gardel ML. Tension is required but not sufficient for focal adhesion maturation without a stress fiber template. J Cell Biol. 2012;196(3):363-74. Epub 2012/01/30. doi: 10.1083/jcb.201107042. PubMed PMID: 22291038.

26. Li C, Sun J, Liu Q, Dodlapati S, Ming H, Wang L, Li Y, Li R, Jiang Z, Francis J, Fu X. The landscape of accessible chromatin in quiescent and post-myocardial infarction cardiac fibroblasts. bioRxiv. 2021:2021.03.03.433814. doi: 10.1101/2021.03.03.433814.

27. Gabbiani G, Ryan G, Majno G. Presence of modified fibroblasts in granulation tissue and their possible role in wound contraction. Experientia. 1971;27(5):549-50.

28. Darby I, Skalli O, Gabbiani G. a-Smooth muscle actin is transiently expressed by myofibroblasts during experimental wound healing. Lab Invest. 1990;63(1):21-9.

29. Jester JV, Rodrigues MM, Herman IM. Characterization of avascular corneal wound healing fibroblasts. New insights into the myofibroblast. Am J Pathol. 1987;127(1):140-8. PubMed PMID: 3565534.

30. Leavitt J, Gunning P, Kedes L, Jariwalla R. Smooth muscle alpha-action is a transformation-sensitive marker for mouse NIH 3T3 and Rat-2 cells. Nature. 1985;316(6031):8402. Epub 1985/08/04. doi: 10.1038/316840a0. PubMed PMID: 4033781.

31. Hinz B, Celetta G, Tomasek JJ, Gabbiani G, Chaponnier C. Alpha-smooth muscle actin expression upregulates fibroblast contractile activity. Mol Biol Cell. 2001;12(9):2730-41. Epub 2001/09/13. doi: 10.1091/mbc.12.9.2730. PubMed PMID: 11553712; PMCID: PMC59708.

32. Chaponnier C, Goethals M, Janmey PA, Gabbiani F, Gabbiani G, Vandekerckhove J. The specific NH2-terminal sequence Ac-EEED of alpha-smooth muscle actin plays a role in polymerization in vitro and in vivo. Journal of Cell Biology. 1995;130(4):887-95. doi: 10.1083/jcb.130.4.887.

33. Hinz B, Gabbiani G, Chaponnier C. The NH2-terminal peptide of a-smooth muscle actin inhibits force generation by the myofibroblast in vitro and in vivo. J Cell Biol. 2002;157(4):657-63. doi: 10.1083/jcb.200201049.

34. Acharya A, Baek ST, Banfi S, Eskiocak B, Tallquist MD. Efficient inducible Cre-mediated recombination in Tcf21 cell lineages in the heart and kidney. Genesis. 2011;49(11):870-7. Epub 2011/03/25. doi: 10.1002/dvg.20750. PubMed PMID: 21432986; PMCID: PMC3279154. 
35. Yamamoto M, Shook NA, Kanisicak O, Yamamoto S, Wosczyna MN, Camp JR, Goldhamer DJ. A multifunctional reporter mouse line for Cre- and FLP-dependent lineage analysis. Genesis. 2009;47(2):107-14. Epub 2009/01/24. doi: 10.1002/dvg.20474. PubMed PMID: 19165827.

36. van Berlo JH, Kanisicak O, Maillet M, Vagnozzi RJ, Karch J, Lin SC, Middleton RC, Marbán E, Molkentin JD. c-kit+ cells minimally contribute cardiomyocytes to the heart. Nature. 2014;509(7500):337-41. Epub 2014/05/09. doi: 10.1038/nature13309. PubMed PMID: 24805242; PMCID: PMC4127035.

37. Sriramula S, Haque M, Majid DSA, Francis J. Involvement of tumor necrosis factor-alpha in angiotensin II-mediated effects on salt appetite, hypertension, and cardiac hypertrophy. Hypertension (Dallas, Tex : 1979). 2008;51(5):1345-51. doi: 10.1161/hypertensionaha.107.102152. PubMed PMID: 18391105.

38. Fu X, Zhu M, Zhang S, Foretz M, Viollet B, Du M. Obesity Impairs Skeletal Muscle Regeneration Through Inhibition of AMPK. Diabetes. 2016;65(1):188-200. Epub 2015/09/17. doi: 10.2337/db15-0647. PubMed PMID: 26384382.

39. Zhu MJ, Ford SP, Means WJ, Hess BW, Nathanielsz PW, Du M. Maternal nutrient restriction affects properties of skeletal muscle in offspring. The Journal of physiology. 2006;575(Pt 1):241-50. Epub 2006/06/08. doi: 10.1113/jphysiol.2006.112110. PubMed PMID: 16763001. 


\begin{tabular}{|l|l|l|}
\hline Target gene & Forward primer & Reverse primer \\
\hline Actg2 & GACTTCTCACACCCTTGGTGCTC & AAGGGCGGTGGTCTCTTCTTCAC \\
\hline Actg1 & TGAGCAAGAAATGGCTACTGCTG & ACAGGACTCCATGCCCAGGAA \\
\hline Actb & TCCTTCTTGGGTATGGAATCCTGT & TTTACGGATGTCAACGTCACACTTC \\
\hline Acta1 & AGACTCCTCCCTCCCCTCTTACT & GGTGTCTAGTTTCAGAGGCTGGC \\
\hline Acta2 & AAGAGCTACGAACTGCCTGACG & GTTTCGTGGATGCCCGCTGA \\
\hline Colc1 1 1 1 & TATAAAGCTGCGCTCCAGGCGA & CTTTGGTGGGTTCTGTAGGCGTG \\
\hline Col3a1 & GACCTGACTGGAAGAGCGGAGAG & GCTGAGTAGGGAACACACAGGTC \\
\hline Lox & GTAACTGCAAACTGCCACGTCCT & AGCGGAGAAGGGGACAAAGCTG \\
\hline $18 S$ & GTAACCCGTTGAACCCCATT & CCATCCAATCGGTAGTAGCG \\
\hline
\end{tabular}

Table 1. Primer sequences used in realtime PCR. 


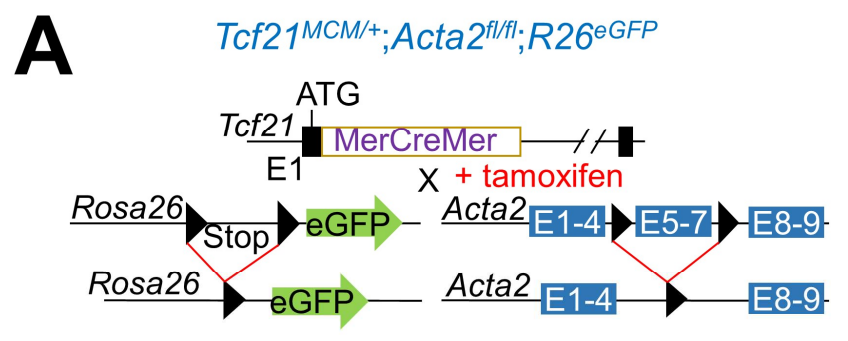

C
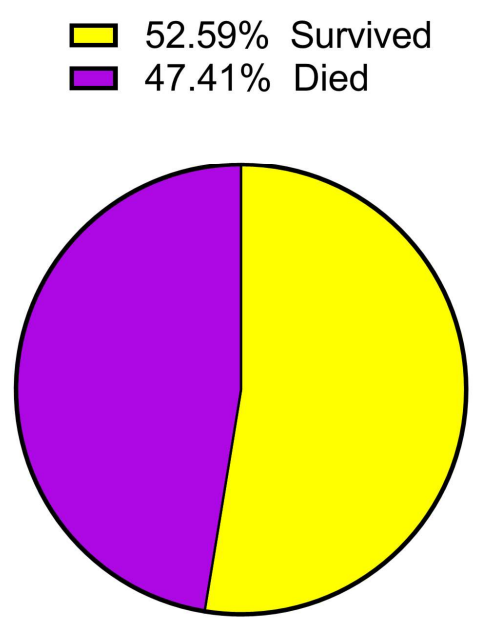

Total $=135$

$T c f 21^{M C M} ; R 26^{\text {EGFP }}$
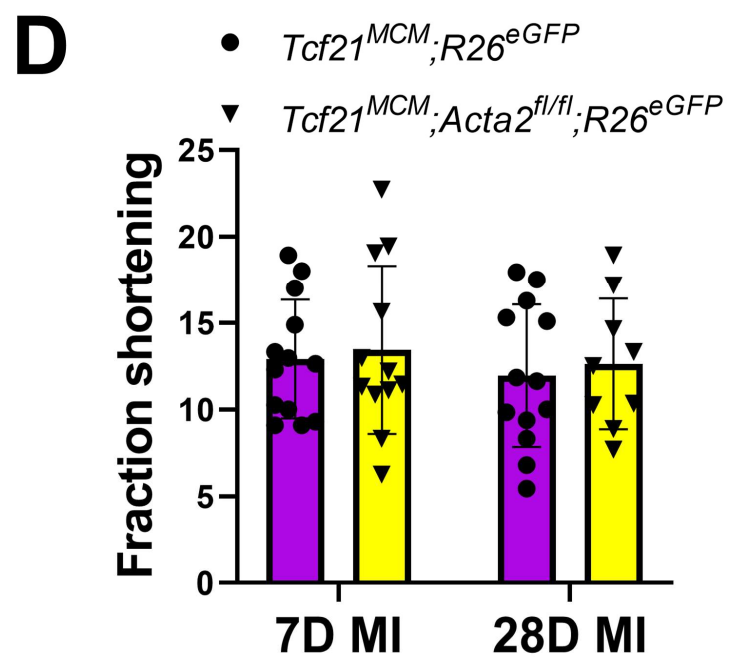

B

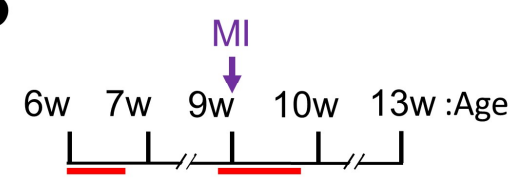

+tamoxifen

$50.91 \%$ Survived
$49.09 \%$ Died

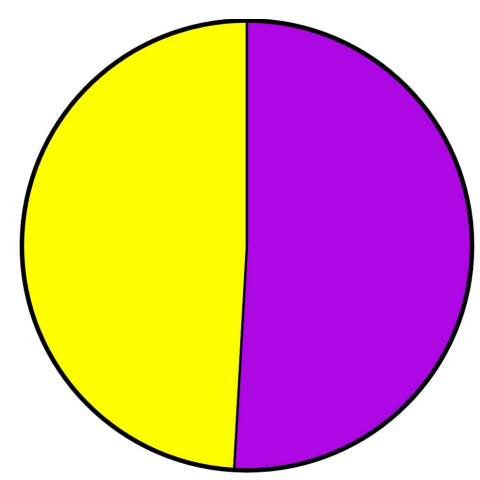

Total $=\mathbf{1 1 0}$

$T c f 21^{M C M} ; A c t a 2^{f l / f l} ; R 26^{e G F P}$

E

- $\quad T C f 21^{M C M} ; R 26^{e G F P}$

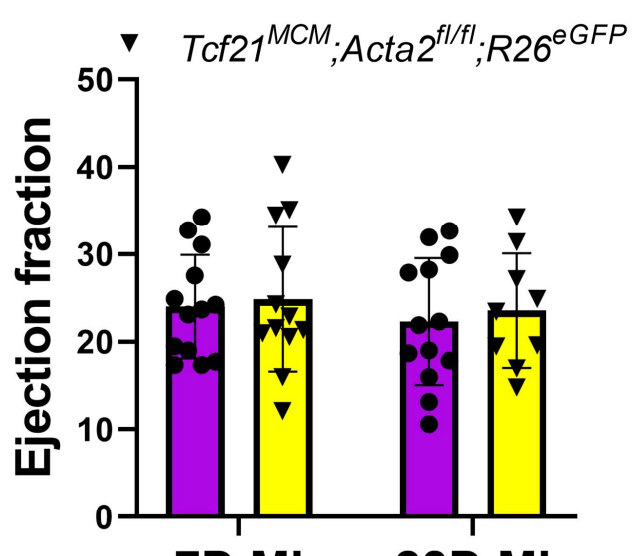

7D MI 28D MI

Figure 1. Cardiac fibroblast-specific deletion of Acta2 does not affect the post-MI survival or cardiac function of mice.

(A) Schematic of the generation of $T c f 21^{M C M /+} ; A c t a 2^{f / f / f l} ; R 26^{e G F P}$ mice. In these mice, a tamoxifenregulated MerCreMer cDNA cassette inserted into exon 1 (E1) enables the tamoxifen-induced 
deletion of the loxP site-flanked stop cassette upstream of eGFP inserted into the $R 26$ locus and the deletion of the loxP site-flanked exons 5-7 (E5-7) of Acta2 only in cells expressing Tcf21. (B) Experimental scheme whereby $T c f 21^{M C M /+} ; R 26^{e G F P}$ and $T c f 21^{M C M /+} ; A c t a 2^{f / f f l} ; R 26^{e G F P}$ mice were given tamoxifen for 5 continuous days starting at 6 weeks of age and rested for 2 weeks before MI surgery. Mice were treated with tamoxifen again every day from one day before MI to 5 days. (C) The percentages of $T c f 21^{M C M /+} ; R 26^{e G F P}$ and $T c f 21^{M C M /+} ; A c t a 2^{f / / f l} ; R 26^{e G F P}$ mice survived or died within the first 7 days after MI. (D-E) Fraction shortening (D) and ejection fraction (E) of Tcf2 $1^{M C M /+} ; R 26^{\text {eGFP }}$ and $T c f 21^{M C M /+} ; A c t a 2^{f / / f l} ; R 26^{e G F P}$ mice at 7 and 28 days after MI. 

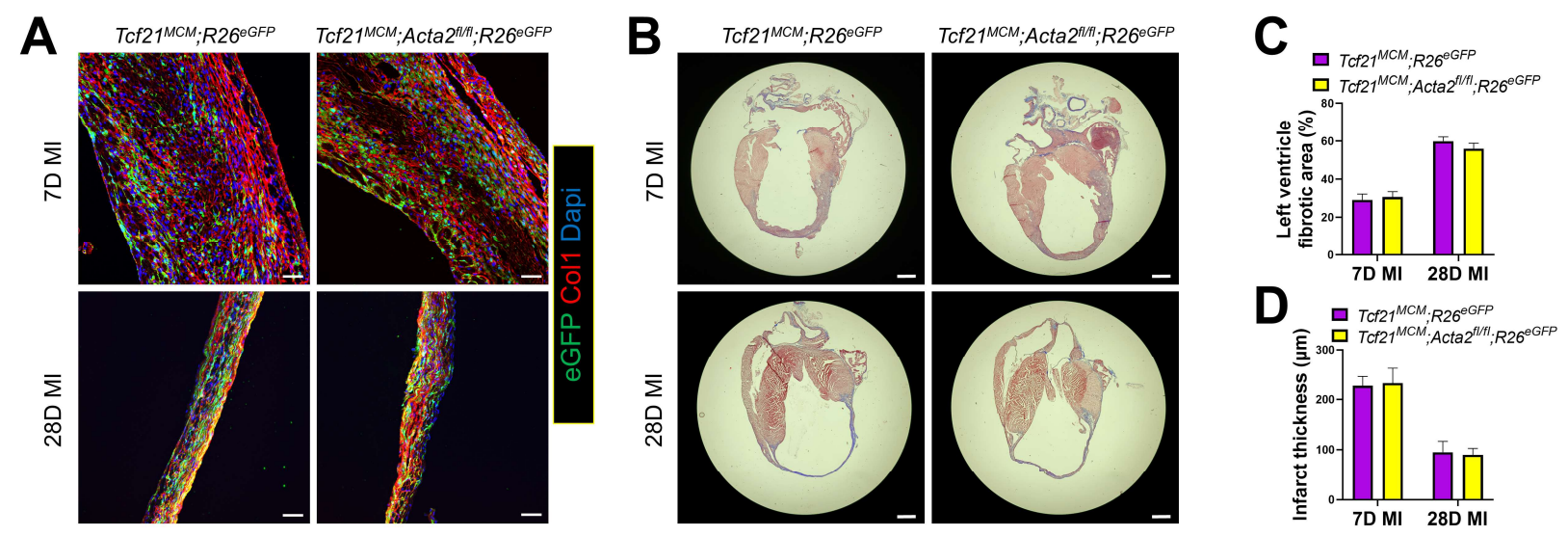

Figure 2. Cardiac fibroblast-specific Acta2 KO mice have normal cardiac remodeling after MI.

Heart samples were collected from tamoxifen-treated Tcf $21^{\mathrm{MCM} /{ }^{+}} ; R 26^{\text {eGFP }}$ and $T c f 21^{M C M /+} ; A c t a 2^{f / f / l} ; R 26^{e G F P}$ mice at 7 and 28 days after MI. (A) Representative IHC images from 5 analyzed hearts per group showing the presence of eGFP ${ }^{+} T c f 21$ lineage-traced cardiac fibroblasts and the expression of type I collagen (Col1). Nuclei are shown with DAPI. Scale bar: $50 \mu \mathrm{m}$. (B) Representative trichrome staining images from 5 analyzed hearts per group showing the dilation of the left ventricle after MI and collagen deposition in the infarct area. Scale bar: 1 $\mathrm{mm}$. (C-D) Percentage of the fibrotic area in the left ventricle (C) and average left ventricle thickness (D) determined by analysis of trichrome staining images using Image $\mathrm{n}=5$. 

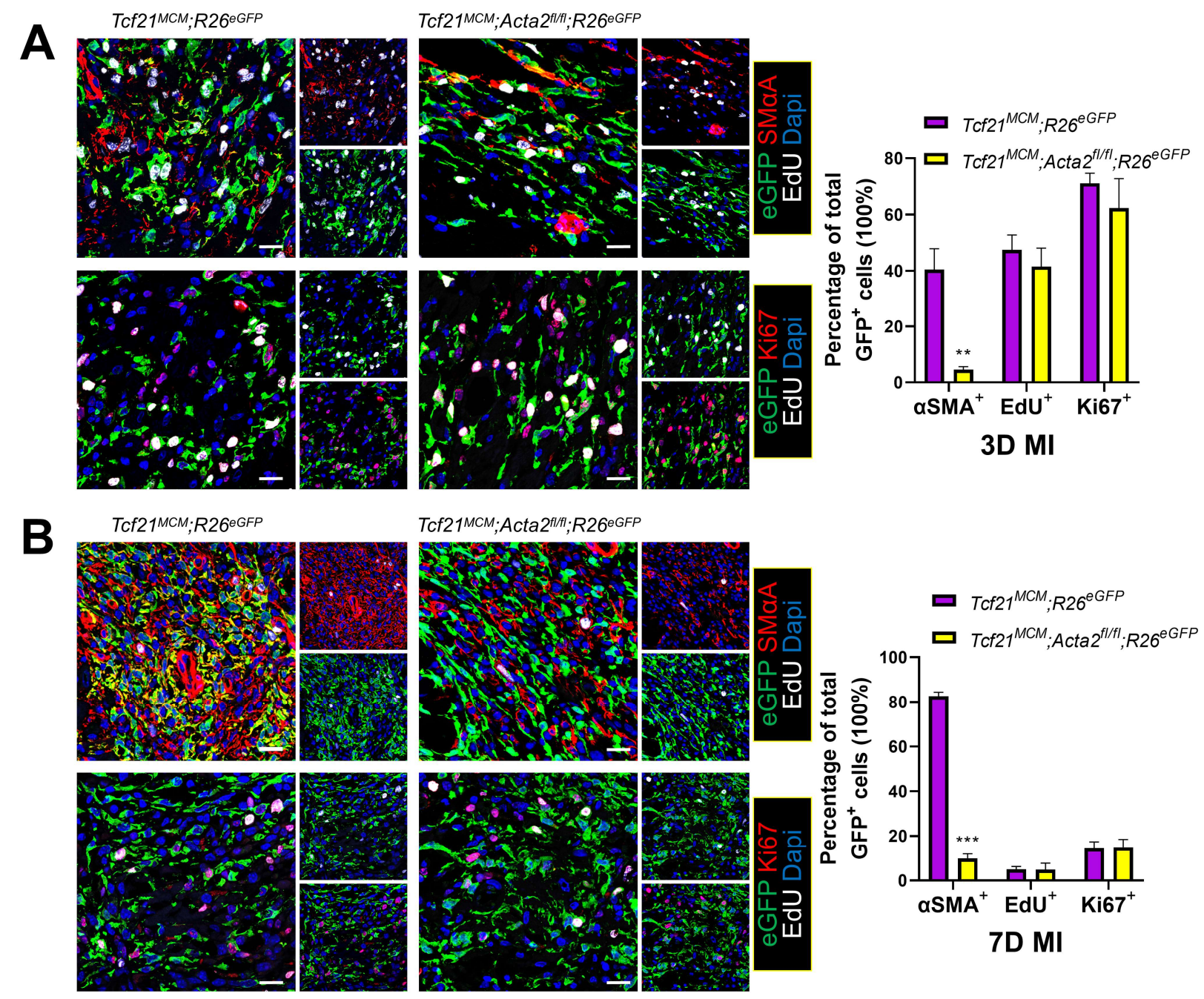

Tcf21MCM;Acta2 ${ }^{\mathrm{fl} / \mathrm{fl} ;}$ :R26 eGFP $^{\text {G }}$
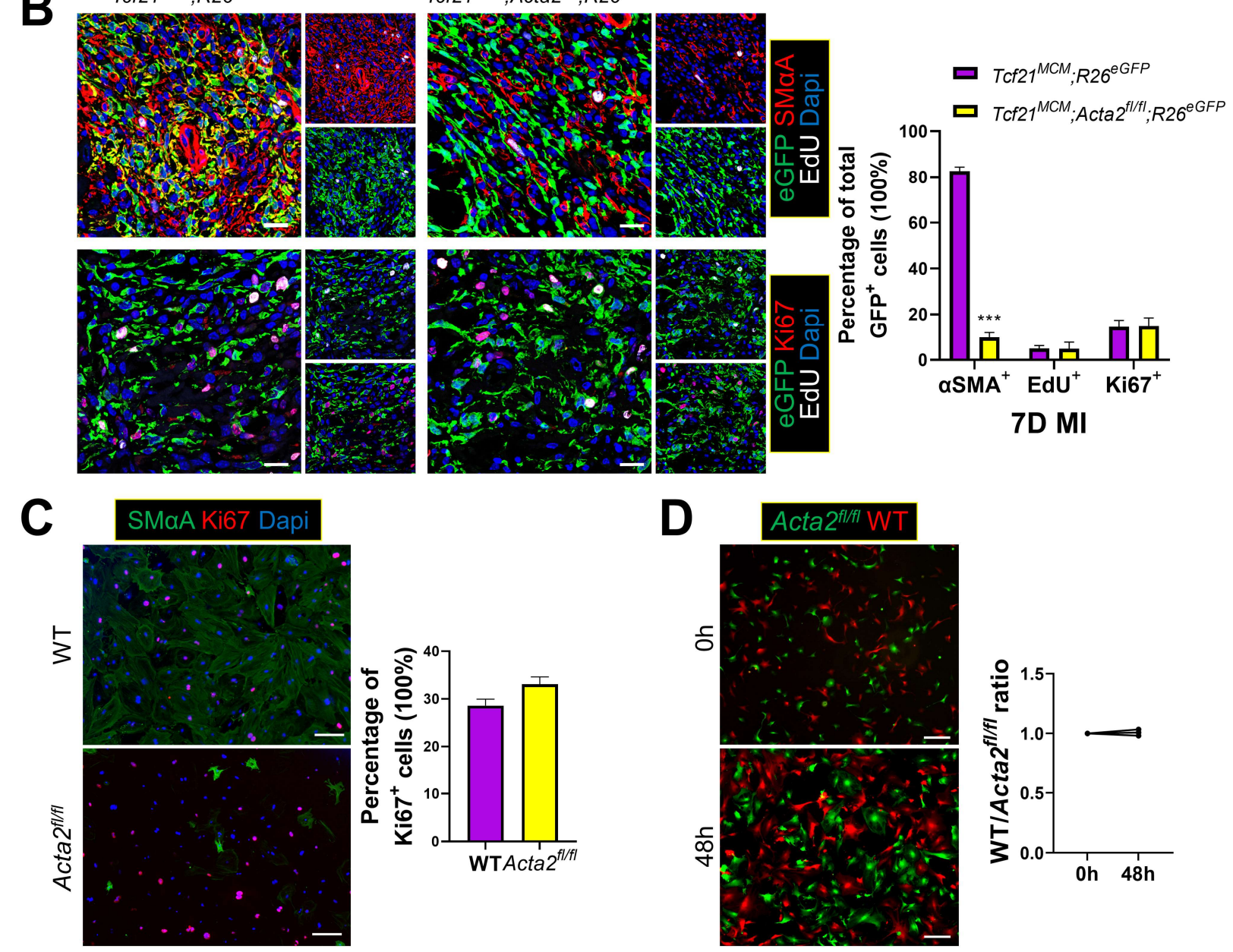

Figure 3. Cardiac fibroblast-specific deletion of Acta2 does not alter cardiac fibroblast proliferation after MI.

(A-B) Tamoxifen-treated $T c f 21^{M C M /+} ; R 26^{\text {eGFP }}$ and $T c f 21^{M C M /+} ; A c t a 2^{f / / f l} ; R 26^{e G F P}$ mice were subjected to MI. Heart samples were collected at 3 days and 7 days post-MI, 4 hours after a single EdU 
injection. IHC was performed to identify and quantify Tcf21 lineage-traced (eGFP ${ }^{+}$cardiac fibroblasts that are positive for SMaA, Ki67, or EdU in the infarct region at 3 days $(A)$ and 7 days (B) after MI. n=3. Scale bar: $20 \mu \mathrm{m}$. (C) Cardiac fibroblasts isolated from WT and Acta2 ${ }^{\text {fl/fl }}$ mice were transduced with Adeno-Cre and treated with TGF $\beta$ for 2 days. ICC was performed to identify the expression of SMaA and Ki67. Nuclei are shown with DAPI. $n=3$. Scale bar: $100 \mu \mathrm{m}$. (D) Cardiac fibroblasts isolated from $R 26^{\text {tdTomato }}(\mathrm{WT})$ and Acta2 $^{\mathrm{fl} / f l} ; R 26^{\mathrm{eGFP}}\left(\right.$ Acta2 $\left.^{\mathrm{fl} / f l}\right)$ mice were transduced with Adeno-Cre and co-cultured at a 1:1 ratio. The ratio between WT and Acta2 $2^{\text {fl/fl }}$ cardiac fibroblasts was calculated again after 48 hours of co-culture in the presence of TGF $\beta$. n=3. Scale bar: $250 \mathrm{~nm} .{ }^{* *} P<0.01 ;{ }^{* *} P<0.0001$. 


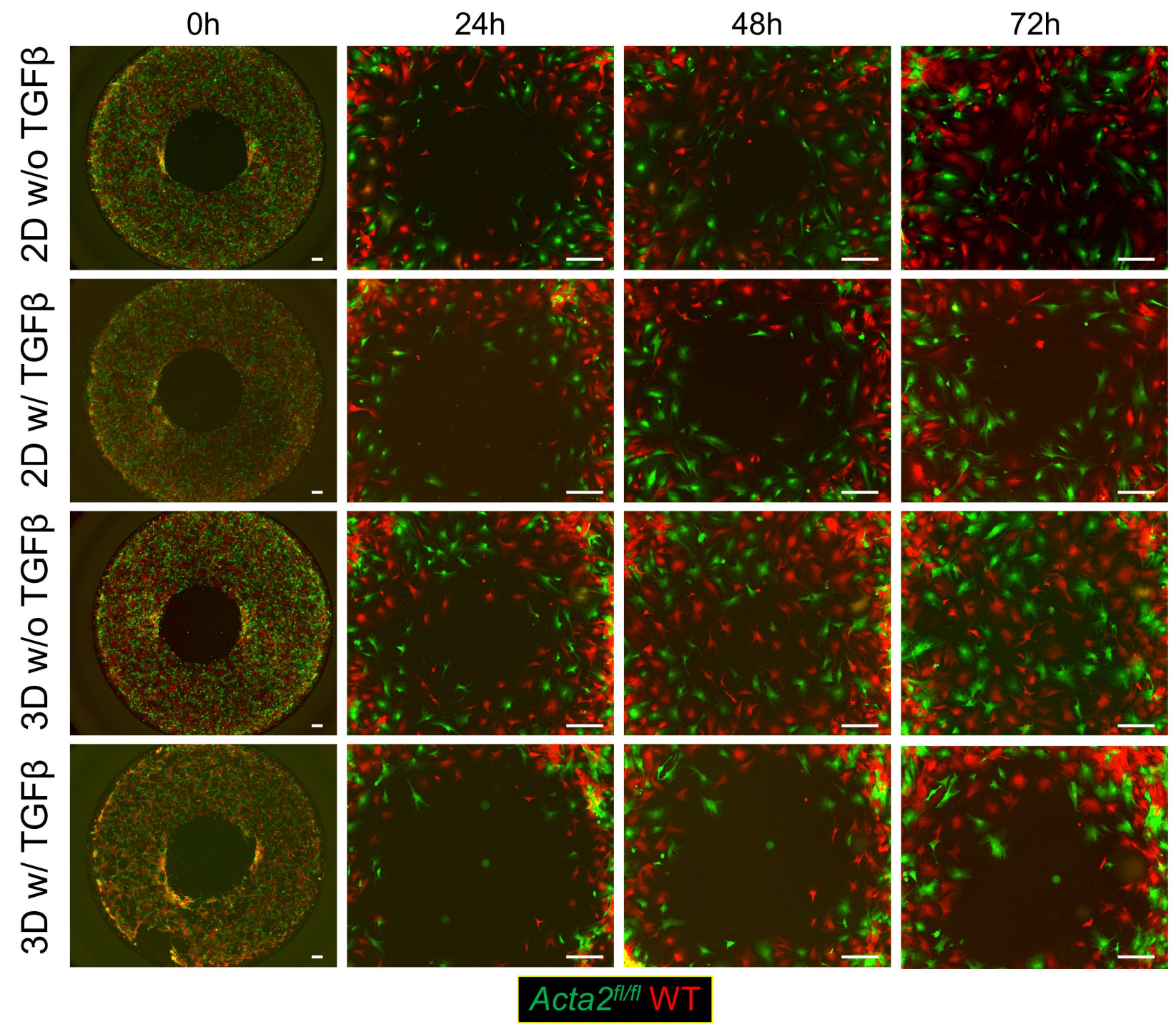

Figure 4. Deletion of Acta2 does not affect the motility of cardiac fibroblasts.

Cardiac fibroblasts isolated from $R 26^{\text {tdTomato }}(\mathrm{WT})$ and Acta2 $2^{f / f f l} ; R 26^{\text {eGFP }}\left(\right.$ Acta2 $\left.^{\text {fl/fl}}\right)$ mice were transduced with Adeno-Cre and seeded onto the same wells of 96 -well plates at a 1:1 ratio with stoppers placed in the center of wells preventing the attachment of cells to the center area of wells. The stoppers were removed after overnight incubation. The migration of cells into the center of wells was monitored every day. For 2D migration, fresh medium with or without TGF $\beta$ supplementation was used in the assay. For 3D migration, a layer of collagen gel was overlayed onto the cells after removing the stoppers, followed by the addition of fresh medium with or without TGF $\beta$ supplementation. Images represent 3 independent replications. Scale bar: $300 \mu \mathrm{m}$. 


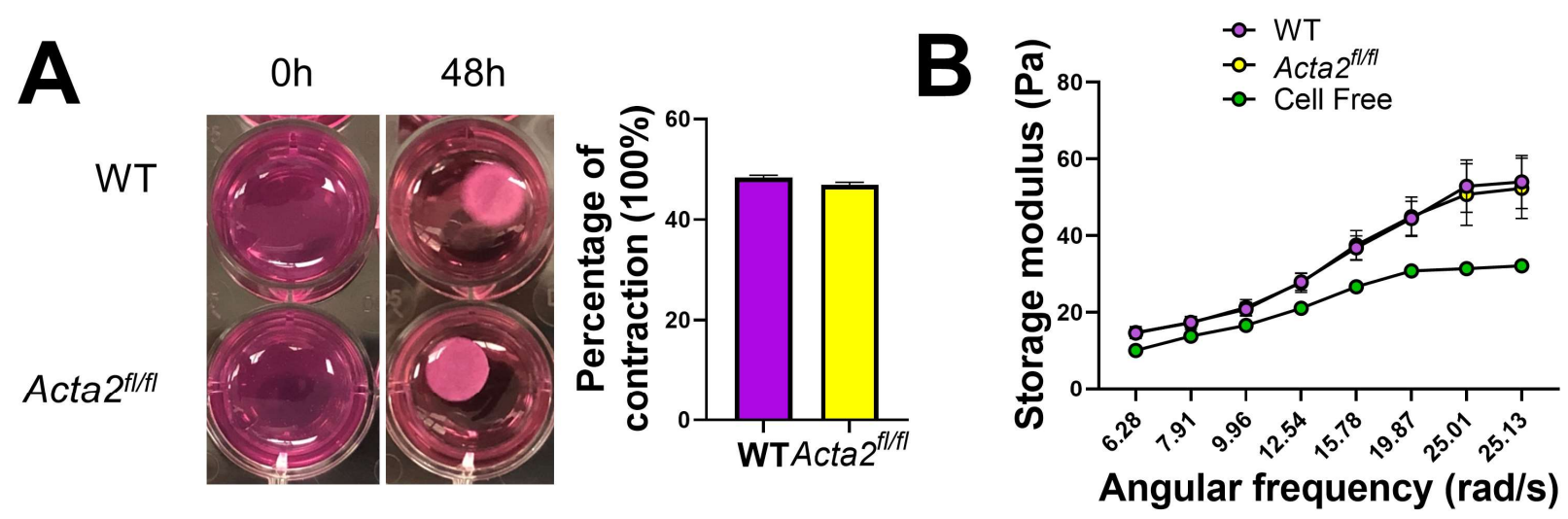

Figure 5. Deletion of Acta2 does not affect the contractility of cardiac fibroblasts and their ability to stabilize the matrix.

Cardiac fibroblasts isolated from WT and Acta2 $2^{f / f t}$ mice were transduced with Adeno-Cre, treated with TGF $\beta$ for 2 days, mixed with collagen gel, and poured onto 24 well plates. (A) Gels were released from wells after 12 hours of incubation. Images and quantification show the degree of contraction of gels 48 hours after the release of gels. $n=3$. (B) The storage moduli of cell-free gels and cell-laden gels 12 hours after incubation were measured using a rheometer. $n=5$. 
A

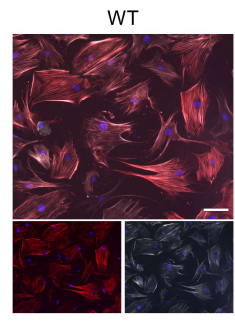

B

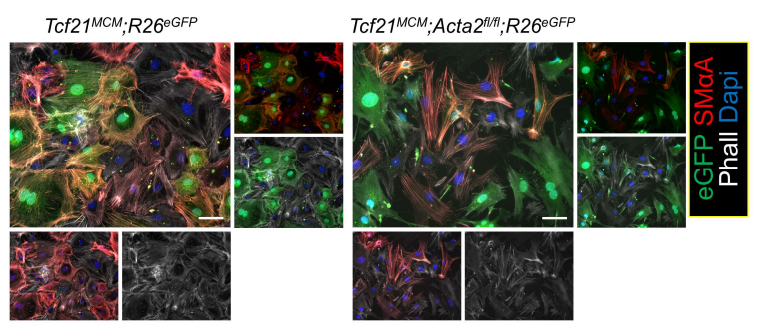

C
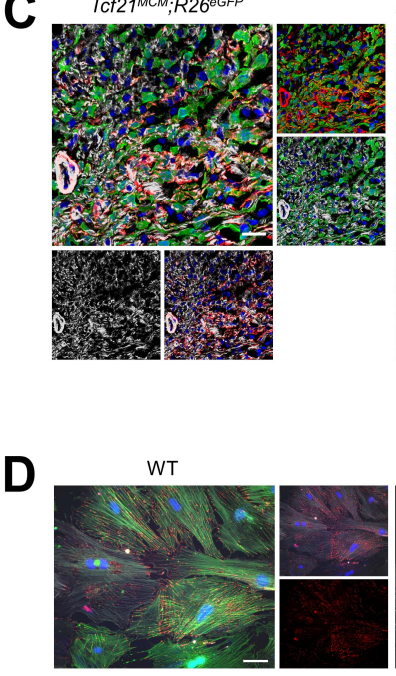

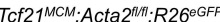

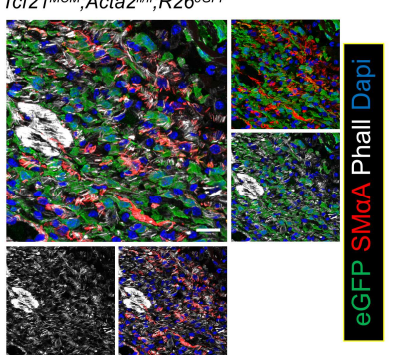

$\operatorname{Acta2^{\text {f/n}}}$

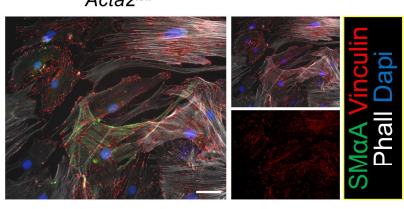

Figure 6. Deletion of Acta2 does not prevent the myofibroblast differentiation of cardiac fibroblasts.

(A) Cardiac fibroblasts isolated from WT and Acta2 $2^{f / f t}$ mice were transduced with Adeno-Cre, treated with TGF $\beta$ for 2 days, and subjected to ICC to identify the expression of SMaA and presence of F-actin using an anti-SMaA antibody and phalloidin (Phall), respectively. Nuclei are shown with DAPI. Scale bar: $100 \mu \mathrm{m}$. The strength of the signal was determined using ImageJ. $\mathrm{n}=3$. (B) Cardiac fibroblasts isolated from tamoxifen-treated $T c f 21^{\mathrm{MCM} / \mathrm{+}} ; R 26^{\mathrm{eGFP}}$ and $T c f 21^{M C M /+} ; A c t a 2^{f / f / l} ; R 26^{\text {eGFP }}$ mice were treated with TGF $\beta$ for 2 days and subjected to ICC to identify the expression of SMaA and presence of F-actin. Nuclei are shown with DAPI. Images represent 3 independent replications. Scale bar: $40 \mu \mathrm{m}$. (C) Tamoxifen-treated $T c f 21^{M C M /+} ; R 26^{e G F P}$ and $T c f 21^{M C M /+} ; A c t a 2^{f / f / f} ; R 26^{e G F P}$ mice were subjected to MI. Heart samples were collected at 7 days post-MI. IHC was performed to identify Tcf21 lineage-traced (eGFP') cardiac fibroblasts that are positive for SMaA or/and phalloidin. Nuclei are shown with DAPI. Images represent 3 analyzed hearts per group. Scale bar: $20 \mu \mathrm{m}$. (D) Cardiac fibroblasts isolated from WT and Acta $2^{f / f t}$ mice were transduced with Adeno-Cre, treated with TGF $\beta$ for 2 days, and subjected to ICC to identify the expression of SMaA and vinculin using specific antibodies. Nuclei are shown with DAPI. Images represent 3 independent replications. Scale bar: $40 \mu \mathrm{m} .{ }^{* \star} P<0.01$. 


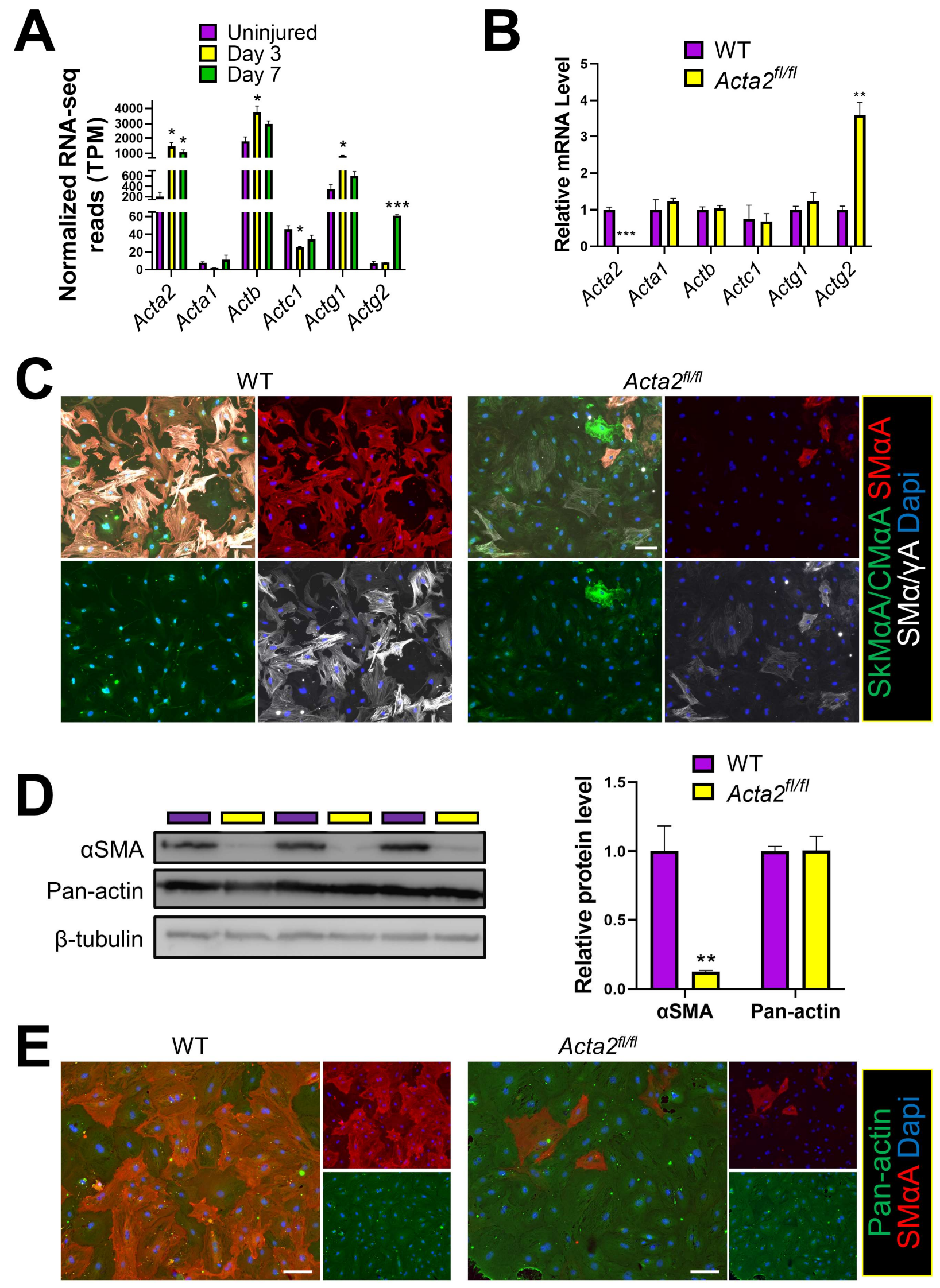


Figure 7. Deletion of Acta2 leads to a compensatory increase in the expression of other actin isoforms and does not affect the total actin expression level.

(A) Tcf21 lineage-traced cardiac fibroblasts sorted from uninjured hearts and the infarct region at 3 days and 7 days after $\mathrm{MI}$ were subjected to RNA-seq. The normalized transcription levels (transcript per million, TPM) of Acta2, Acta1, Actb, Actc1, Actg1, and Actg2 are shown. (B) Cardiac fibroblasts isolated from WT and Acta2 $2^{\mathrm{flft}}$ mice were transduced with Adeno-Cre and treated with TGF $\beta$ for 2 days. RNA was extracted from these cells and used for cDNA synthesis. The transcription levels of Acta2, Acta1, Actb, Actc1, Actg1, and Actg2 were revealed by realtime PCR. (C) Cardiac fibroblasts isolated from WT and Acta2 ${ }^{f / f t}$ mice were transduced with AdenoCre, treated with TGF $\beta$ for 2 days, and subjected to ICC to identify the protein level of SMaA, the combined protein level of SkMaA and CMaA, and the combined protein level of SMaA and SMyA. Nuclei are shown with DAPI. Images represent 3 independent replications. Scale bar: $100 \mu \mathrm{m}$. (D-E) Cardiac fibroblasts isolated from WT and Acta2 ${ }^{f / f t}$ mice were transduced with Adeno-Cre and treated with TGF $\beta$ for 2 days. Western blot (D) and ICC (E) were performed to quantify SMaA and total actin protein levels using an anti-SMaA antibody and an antibody that recognizes all actin isoforms, respectively. $\mathrm{n}=3$. ${ }^{*} P<0.05$; ${ }^{* *} P<0.01$; ${ }^{* * *} P<0.0001$. 